\title{
EVALUASI PERBANDINGAN SIMPANGAN STRUKTUR SRPM AKIBAT PERMODELAN STRUKTUR YANG BERBEDA
}

\author{
Tondi Amirsyah Putera1, Ade Faisal'2, Suprayetno ${ }^{3}$ \\ 1,2,3Dosen Pengajar Program Studi Teknik Sipil, Fakultas Teknik, UMSU, Medan \\ 1Surel : tondimt@gmail.com \\ Diterima : 10 Mei 2018; Disetujui : 25 Mei 2018
}

\begin{abstract}
ABSTRAK
Struktur bangunan bertingkat rawan terhadap gaya lateral, terutama akibat gaya yang ditimbulkan oleh gempa. Indonesia juga termasuk ke dalam wilayah yang memiliki instensitas terjadi gempa yang tinggi. Dalam menghitung struktur bangunan bertingkat ada 2 cara, yakni dengan sistem rangka pemikul momen (SRPM) dan kombinasi SRPM dengan shear wall. Pada proses perencanaan umumnya dinding geser dimodelkan sebagai element solid pada program komputer. Pemakaian element solid ini akan memakan waktu analisa seiring dengan semakin bertambahnya tinggi bangunan. Dinding geser juga dapat dimodelkan dengan element garis (line). Untuk itu studi ini bertujuan membandingkan hasil yang diperoleh bila dinding geser dimodelkan sebagai element solid dan element garis. Pada studi ini terdapat 3 pemodelan struktur, yaitu 1 model strktur tanpa dinding geser, dan 2 model truktur dengan dinding geser (model dinding geser solid element dan model dinding geser line element). Semua input beban, tingkat kekakuan dan dimensi struktur adalah sama, yang berbeda hanyalah model shear wall yang digunakan. Gedung ini memiliki tingggi 40 meter (10 lantai), tinggi tiap lantai 4 meter. Berdasarkan hasil analisis tersebut diperoleh bahwa terjadi perbedaan perioda getar, simpangan, gaya geser dasar dan gaya-gaya dalam karena pemodelan sistem struktur penahan gaya geser yang berbeda-beda.
\end{abstract}

Kata Kunci : Dinding Geser, Pemodelan Struktur, Simpangan

\begin{abstract}
The structure of multi-storey buildings are vulnerable to lateral force, especially due to the force created by the earthquake. Indonesia is also included in the territory which has instensitas an earthquake is high. In calculating the structure of multi-storey buildings there are two ways, namely as moment resisting frame system (MRF) and combination of MRF with shear wall. The development of science and technology has given rise to one of the solutions to improve the performance of high-level structure, namely the installation of shear walls to add structural rigidity and absorbs shear forces along with the high structure. The goal of this studi is to determine the difference of some parameters made of a combination of structural design of the building with MRF and MRF with shear wall. In this study, there are 3 modeling of structures, namely 1 models structure without shear walls, and two models of structures are at the shear wall (solid element model of shear walls and shear wall model line element). All input load, stiffness and dimensional structure is the same, just different shear wall models used. This building has 40 meters (10 floors) of height, which is the height of each floor 4 meters. The results of the analysis indicates that the significant deviation occurs due to system modeling of shear wall is different.
\end{abstract}

Keywords: Shear Wall, Structure Modelling, Displacement 


\section{Pendahuluan}

Ilmu pengetahuan dan penerapan teknologi dalam bidang pembangunan konstruksi teknik sipil mengalami perkembangan yang pesat, membuat kita dituntut untuk lebih produktif, kreatif dan inovatif, terutama dalam hal perancangan struktur. Salah satu kriteria dalam merencanakan struktur bangunan bertingkat adalah kekuatan, kekakuan serta perilaku bangunan tinggi (Pawirodikromo, 2012).

Indonesia merupakan negara yang terus berkembang pesat, ini berdampak kepada pembangunan di berbagai wilayah. Sejalan dengan perkembangan teknologi kontruksi saat ini, banyak struktur bangunan konstruksi yang telah mengalami perubahan. Sekarang telah banyak dibuat bangunan-bangunan bertingkat tinggi dengan model struktur yang sangat rumit dan arsitektur yang sangat indah. Tentu saja untuk mendesain dan membuat struktur bangunan seperti itu tidaklah mudah.

Indonesia merupakan salah satu negara dengan aktivitas gempa yang tinggi. Hal ini disebabkan lokasi Indonesia yang terletak pada pertemuan empat lempeng tektonik utama yaitu Lempeng Eurasia, Indo-Australia, Pasifik, dan Filipina. Pertemuan lempeng-lempeng tersebut mengakibatkan mekanisme tektonik dan kondisi geologi Indonesia mengakibatkan seringnya terjadi gempa. Hal ini menyebabkan gedung mengalami simpangan lateral (drift) dan apabila simpangan lateral (drift) ini melebihi syarat aman yang telah ditetapkan oleh peraturan yang ada maka gedung akan mengalami keruntuhan. Untuk mengatasi hal tersebut beberapa elemen dari sebuah struktur harus didesain sedemikian rupa sehingga mampu menahan gaya-gaya lateral (beban gempa) yang terjadi (Hasan dan Astira 2013).

Ada beberapa cara yang dapat dilakukan untuk menahan gaya lateral dari beban gempa antara lain:

a. Pemasangan dinding geser (shearwall) pada struktur.

b. Perbesaran dimensi kolom dan balok.

c. Penambahan pengakuan lateral (bracing) pada elemen struktur portal.

Salah satu solusi yang digunakan untuk meningkatkan kinerja struktur bangunan tingkat tinggi adalah dengan pemasangan dinding geser (shearwall). Atas dasar solusi tersebut, maka penelitian ini dimaksudkan untuk membandingkan besarnya simpangan struktur rangka pemikul momen dengan dinding geser, akibat pemodelan struktur yang berbeda. Struktur dapat dikatakan aman apabila nilai simpangan lateralnya tidak melampaui kinerja batas layan gedung dan kinerja batas ultimit.

\section{Kajian Pustaka}

\subsection{Dinding Geser (Shear Wall)}

Dinding geser merupakan dinding yang dirancang untuk menahan gaya geser, gaya lateral akibat gempa bumi. Dinding geser juga merupakan elemen-elemen vertikal sebagai sistem penahan gaya horizontal. Dinding geser harus diletakkan pada tiap tingkat struktur tanpa spasi (menerus). Dinding geser lebih efisien apabila bentuknya lurus vertikal dan didukung oleh pondasi dinding. Apabila dinding geser tidak lurus, maka bagian lain gedung akan membutuhkan penambahan kekuatan.

Dinding geser harus memberikan kekuatan lateral yang dibutuhkan untuk menahan gaya gempa horizontal. Apabila dinding geser cukup kuat, ia akan memindahkan gaya-gaya horizontal ini pada elemen berikutnya pada bagian muatan dibawahnya. Komponenkomponen lain boleh jadi selain dinding geser, lantai, pondasi tiang dan pelat. Dinding geser juga memberikan kekakuan lateral untuk mencegah atap dan lantai atas dari goyangan kesamping yang berlebihan. Jika dinding geser cukup kaku, ia akan mencegah lantai dan rangka atap dari gerakan pendukungnya.

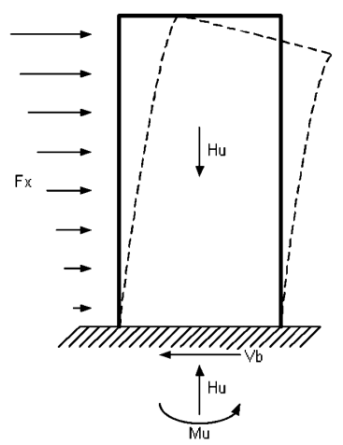

Gambar 1. Gaya-Gaya Yang Bekerja Pada Dinding Geser (Yuliari dan Suhelda, 2008)

\subsection{Fungsi Dinding Geser}

Menurut (Yuliari dan Suhelda, 2008) fungsi dinding geser ada 2, yaitu sebagai kekuatan dan kekakuan, artinya:

a. Kekuatan

Dinding geser harus memberikan kekuatan lateral yang dibutuhkan untuk menahan gaya gempa horizontal. Apabila dinding geser cukup kuat, dinding akan 
memindahkan gaya-gaya horizontal ini pada element berikutnya pada bagian muatan dibawahnya. Komponenkomponen lain pada muatan ini boleh jadi selain dinding geser, lantai, pondasi, dinding bata dan pelat.

b. Kekakuan

Dinding geser juga memberikan kekakuan lateral untuk mencegah atap dan lantai atas dari goyangan arah horizontal yang berlebihan. Jika dinding geser cukup kaku, dinding akan mencegah lantai dan rangka atap dari gerakan horizontal.

\section{Metodologi}

\subsection{Pemodelan Dan Idealisasi Struktur}

Pada penelitian ini pemilihan jenis analisa yang digunakan yaitu prosedur analisis respon spektrum. Struktur gedung memiliki tinggi 40 meter, dengan tinggi antar lantai 4 meter dan gedung menggunakan Sistem Rangka Pemikul Momen Menengah (SRPMM). Respon spektrum yang digunakan pada daerah kota Medan mengacu pada SNI 1726:2012 dengan jenis tanah sedang.

Semua model simetris beraturan dengan sisi lebar dan panjang sama, yaitu 17 meter. Tinggi setiap lantai gedung adalah 4 meter, dengan jumlah lantai sebanyak 10 lantai. Gedung yang pertama ini dimodelkan tanpa dinding geser, model kedua dengan dinding geser solid element, dan model yang ketiga dengan dinding geser line element. Berdasarkan data di atas dapat dilihat ketiga gambar pemodelan gedung pada Gambar 2 sebagai berikut.
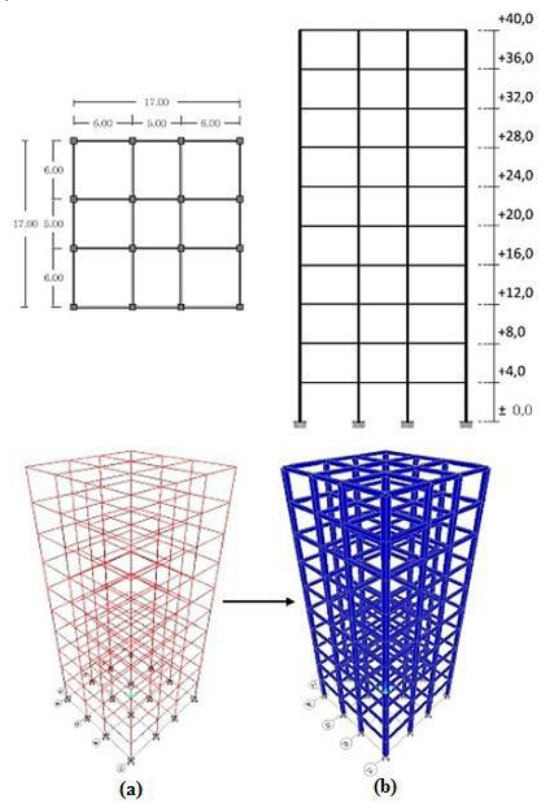

(a)
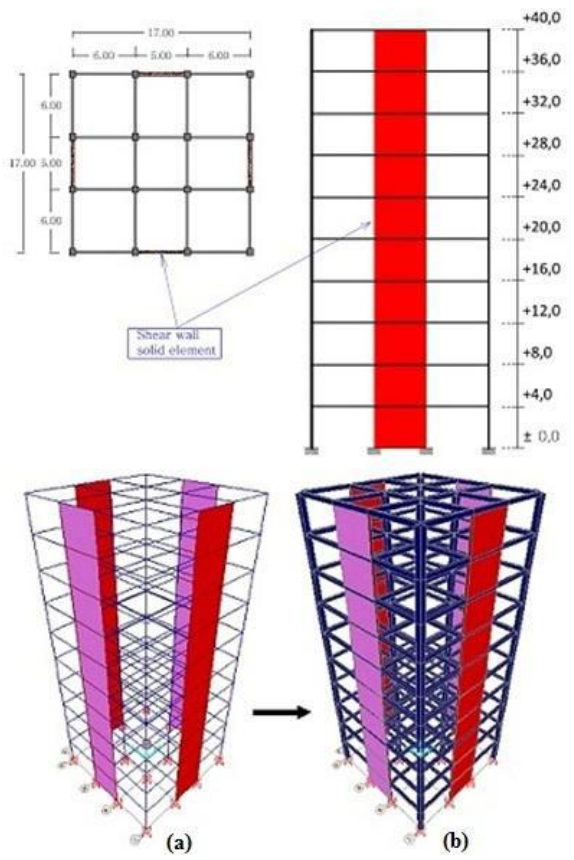

(b)
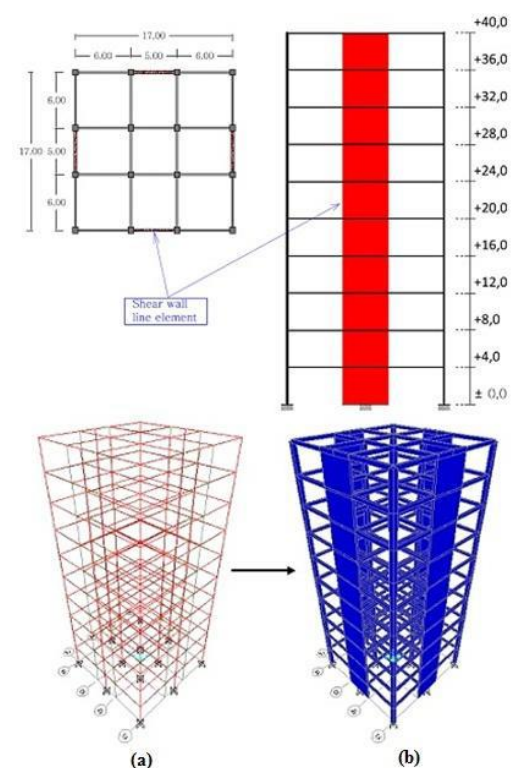

(c)

Gambar 2. Bentuk Tipikal Model Struktur (A) Model 1 SRPMM (B) Model 2 Dinidng Geser Solid (C) Model 3 Dinding Geser Line

\subsection{Data Perencanaan Struktur}

a. Jenis portal struktur gedung beton bertulang.

b. Fungsi gedung perkantoran

c. Gedung terletak di Provinsi Sumatera Utara (Medan)

d. Gedung didesain berdasarkan SRPMM (Struktur Rangka Pemikul Momen Menengah) 
e. Kuat tekan beton yang digunakan $f^{\prime \prime} c=$ $30 \mathrm{MPa}$

f. Kuat leleh baja tulangan $f y=390 \mathrm{MPa}$.

g. Direncanakan jenis tanah sedang (SD)

\subsection{Pembebanan Pada Balok Struktur}

Semua input beban area pada balok struktur, baik beban mati, beban hidup, maupun beban tambahan yang tertumpu pada balok dijadikan sebagai beban merata " $\mathrm{q}_{\mathrm{eq}}$ " $\left(\mathrm{kg} / \mathrm{m}^{\prime}\right)$ pada balok dengan metode amplop. Nilai beban tersebut sengaja diubah menjadi beban $q_{e q}$ dengan metode amplop dimaksudkan untuk mempermudah analisa pada SAP2000 dan mempercepat proses analisa. Adapun hasil persamaan yang dibuat untuk menurunkan rumus beban area $\left(\mathrm{kg} / \mathrm{m}^{2}\right)$ menjadi beban merata $\mathrm{q}_{\mathrm{eq}}\left(\mathrm{kg} / \mathrm{m}^{\prime}\right)$ dapat dilihat pada Gambar 3 dibawah ini.

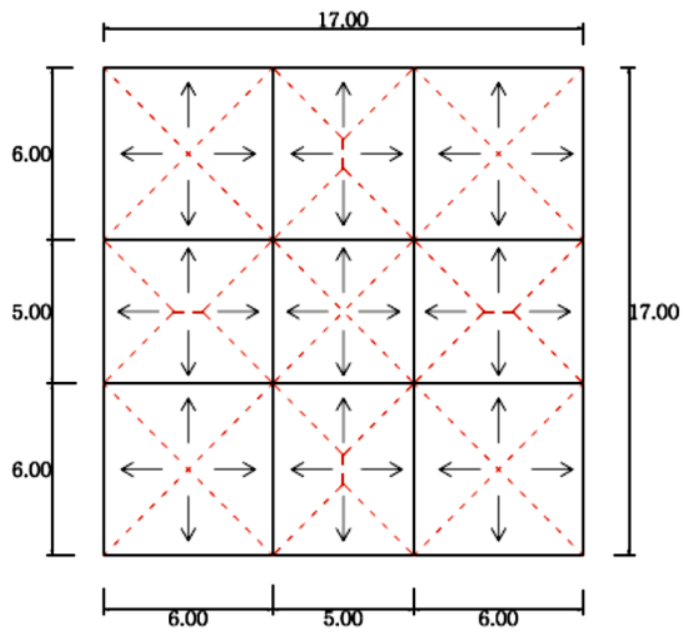

Gambar 3. Penyaluran Beban Pelat Lantai Ke Balok Dengan Metode Amplop

Pada Gambar 3 menjelaskan prinsip penyaluran beban pelat lantai ke balok dengan menggunakan metode amplop. Metode ini dibuat untuk mendapatkan nilai pembebanan pada tiap masing-masing balok, di mana beban segi tiga dan trapesium diturunkan dengan beberapa rumus, sehingga didapatkan suatu persamaan rumus beban garis " $q_{e q}$ " $(\mathrm{kg} / \mathrm{m}$ ') Adapun metode ini dimaksudkan untuk mempercepat proses Run Analysis pada SAP2000.

Berikut gambar 4 dan gambar 5 menampilkan hasil persamaan penurunan rumus beban amplop menjadi beban garis:
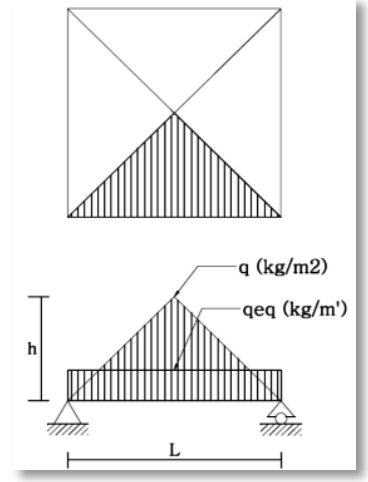

Gambar 4. Perubahan Beban Segi Tiga Ke Beban Garis

Berdasarkan penurunan rumus beban, untuk beban merata segi tiga $\left(\mathrm{kg} / \mathrm{m}^{\prime}\right)$, menjadi beban garis $q_{e q}\left(\mathrm{~kg} / \mathrm{m}^{\prime}\right)$, maka didapatkan Persamaan 1 di bawah ini:

$$
q e q=\frac{2}{3} \cdot q \quad(\mathrm{kN} / \mathrm{m})
$$

Berdasarkan rumus diatas dipakailah nilai qeq sebagai input beban ke balok, oleh SAP2000.

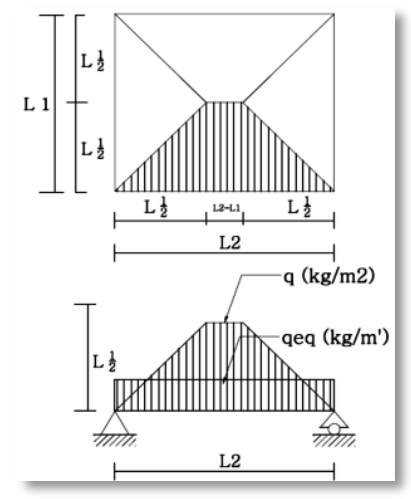

Gambar 5. Perubahan Beban Trapesium Ke Beban Garis

Berdasarkan penurunan rumus beban, untuk beban merata trapesiuma $\left(\mathrm{kg} / \mathrm{m}^{\prime}\right)$, menjadi beban garis $q_{\text {eq }}\left(\mathrm{kg} / \mathrm{m}^{\prime}\right)$, maka didapatkan Persamaan 1 di bawah ini:

$$
q e q=3 \cdot q+\frac{q \cdot L_{1}^{2}}{3 \cdot L_{2}^{2}} \quad(\mathrm{kN} / \mathrm{m})
$$

Berdasarkan rumus diatas dipakailah nilai qeq sebagai input beban ke balok, oleh SAP2000.

\section{Hasil dan Pembahasan}

4.1 Perbandingan Gaya Geser Pada Struktur

Berdasarkan SNI 1726:2012, nilai akhir dinamik struktur gedung tergantung oleh massa beban gravitasi terhadap sistem struktur 
akan mempengaruhi besar gayageser yang bekerja terhadap struktur. Untuk itu akan diperlihatkan perbedaan dari setiap model akibat pengaruh sistem model pada Tabel 1 dibawah ini.

Tabel 1. Gaya Geser Dasar Nominal Hasil Analisis Ragam Respon Spektrum Model 1.

\begin{tabular}{cccccc}
\hline \multicolumn{6}{c}{ TABLE: Base Reactions } \\
\hline $\begin{array}{c}\text { Output } \\
\text { Case }\end{array}$ & $\begin{array}{c}\text { Case } \\
\text { Type }\end{array}$ & $\begin{array}{c}\text { Step } \\
\text { Type }\end{array}$ & $\begin{array}{c}\text { Global } \\
\text { FX }\end{array}$ & $\begin{array}{c}\text { Global } \\
\text { FY }\end{array}$ & $\begin{array}{c}\text { Global } \\
\text { FZ }\end{array}$ \\
\hline Text & Text & Text & KN & KN & KN \\
\hline $\begin{array}{c}\text { GEMPA } \\
\text { Lin }\end{array}$ & $\begin{array}{c}\text { Resp } \\
\text { Spec }\end{array}$ & Max & 1826 & 547,8 & $3,74 \mathrm{E}-12$ \\
\hline $\begin{array}{c}\text { GEMPA } \\
\text { Lin } \\
\text { Resp } \\
\text { Spec }\end{array}$ & & & & & \\
\hline
\end{tabular}

Tabel 2. Gaya Geser Dasar Nominal Hasil Analisis Ragam Respon Spektrum Model 2.

\begin{tabular}{|c|c|c|c|c|c|}
\hline \multicolumn{6}{|c|}{ TABLE: Base Reactions } \\
\hline $\begin{array}{l}\text { Output } \\
\text { Case }\end{array}$ & $\begin{array}{l}\text { Case } \\
\text { Type }\end{array}$ & $\begin{array}{l}\text { Step } \\
\text { Type }\end{array}$ & $\begin{array}{c}\text { Global } \\
\text { FX }\end{array}$ & $\begin{array}{c}\text { Global } \\
F Y\end{array}$ & $\begin{array}{c}\text { Global } \\
\text { FZ }\end{array}$ \\
\hline Text & Text & Text & $\mathrm{KN}$ & $\mathrm{KN}$ & $\mathrm{KN}$ \\
\hline $\begin{array}{c}\text { GEMPA } \\
X\end{array}$ & $\begin{array}{c}\text { Lin } \\
\text { Resp } \\
\text { Spec }\end{array}$ & $\operatorname{Max}$ & 1612,748 & 483,826 & 3,92E-10 \\
\hline $\begin{array}{c}\text { GEMPA } \\
Y\end{array}$ & $\begin{array}{l}\text { Lin } \\
\text { Resp } \\
\text { Spec }\end{array}$ & $\operatorname{Max}$ & 483,825 & 1612,751 & $9,09 \mathrm{E}-10$ \\
\hline
\end{tabular}

Tabel 3. Gaya Geser Dasar Nominal Hasil Analisis Ragam Respon Spektrum Model 3.

\begin{tabular}{cccccc}
\hline \multicolumn{7}{c}{ TABLE: } & Base Reactions \\
\hline $\begin{array}{c}\text { Output } \\
\text { Case }\end{array}$ & Case & Step & Global & Global & Global \\
Type & Type & FX & FY & FZ \\
\hline Text & Text & Text & KN & KN & KN \\
\hline GEMPA & Lin & & & & \\
X & $\begin{array}{c}\text { Resp } \\
\text { Spec Max }\end{array}$ & 1604,929 & 481,479 & $2,89 \mathrm{E}-12$ \\
& Spe & & & \\
\hline GEMPA & Lin & & & & \\
Resp & Max & 481,479 & 1604,929 & $8,17 \mathrm{E}-12$ \\
& Spec & & & & \\
\hline
\end{tabular}

Dapat terlihat bahwa dengan sistem struktur dinding geser gaya geser gempa dapat turun berkisar $13 \%$ dari setiap arah dari struktur system struktur SRPMM, dan untuk sistem dinding geser solid terhadap dinding geser line dapat perbedaan sekitar 0,5\%. Dengan demikian system solid dan line tidak jauh berbeda, pendekatan dinding geser dengan system line masih dimungkinkan untuk digunakan

\subsection{Perbandingan Gaya Geser Gedung Perlantai}

Pada gambar dibawah ini ditampilkan perbandingan gaya geser dari pemodelan gedung yang berbeda yang bekerja pada tiap lantai gedung.

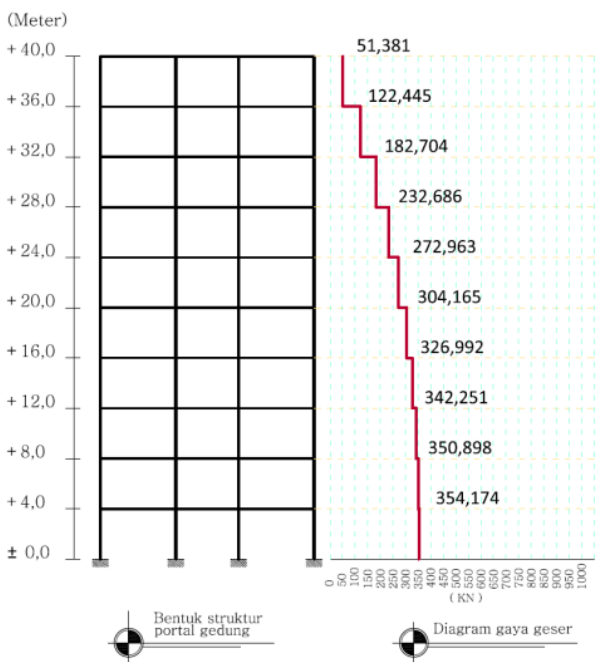

(a)

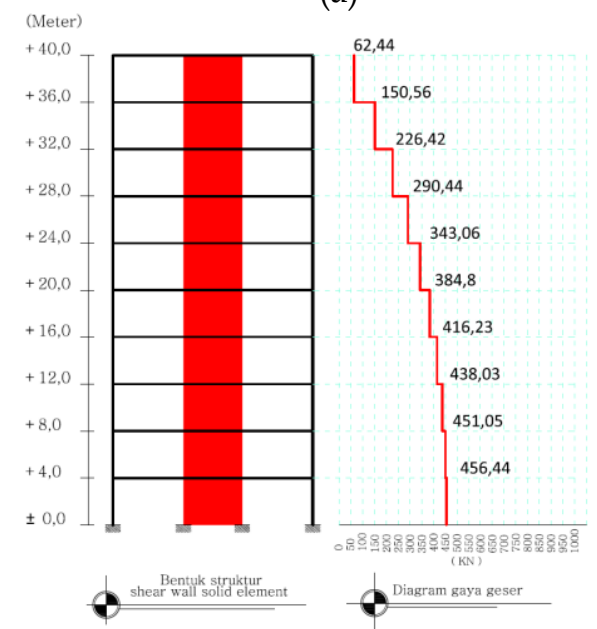

(b)

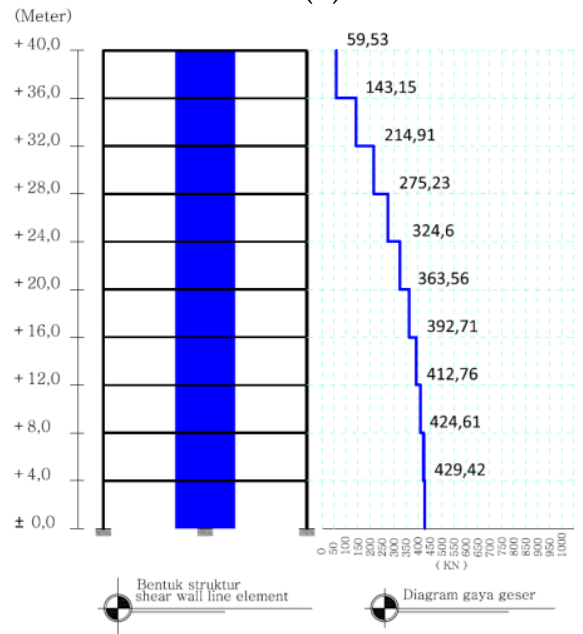

(c)

Gambar 6. Diagram Gaya Geser Terhadap Ketinggian Gedung (A) Model 1 (B) Model 2 dan (C) Model 3 
Dari gambar diagram perbandingan gaya geser diatas, dapat dilihat bahwasannya gaya geser terbesar pada shear wall solid element (Model 2), selanjutnya model shear wall line element dan yang paling kecil gaya gesernya adalah pada Model 1, struktur portal tanpa dinding geser.

Perbedaan gaya geser yang terjadi pada ketiga model diatas diakibatkan oleh berbedanya massa/berat struktur itu sendiri. Semakin berat massa struktur bangunan, maka semakin besar pula gaya geser yang bekerja. Massa/berat sendiri struktur bangunan tersebut juga akan berpengaruh kepada perioda getar struktur. Semakin kaku struktur bangunan, maka perioda getar struktur semakin kecil dan memiliki frekwensi yang semakin tinggi, begitu juga sebaliknya.

\subsection{Perbandingan Simpangan}

Kinerja batas layan struktur gedung ditentukan oleh simpangan antar tingkat akibat pengaruh gempa rencana, yaitu untuk membatasi terjadinya pelelehan baja dan peretakan beton. Pada Gambar dibawah ini ditampilkan nilai simpangan untuk setiap model struktur.

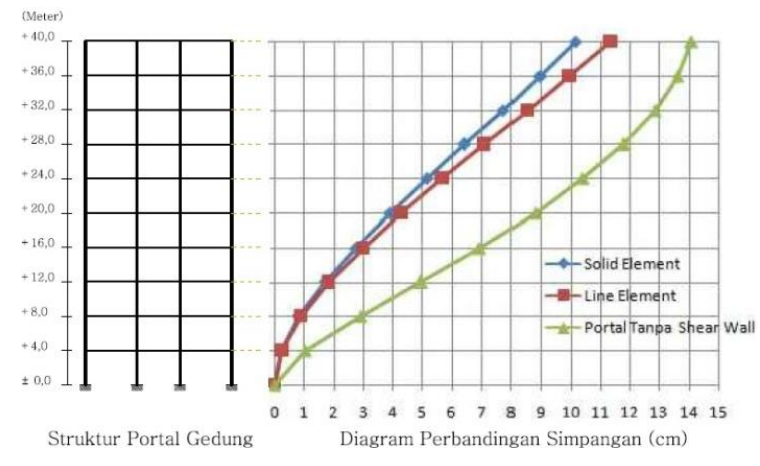

Gambar 7. Diagram Perbandingan Simpangan (Model 1, 2, dan 3)

Dari Gambar diagram perbandingan simpangan diatas, dapat dilihat bahwasannya simpangan terbesar pada struktur Model 1, yaitu 14,08 cm, selanjutnya Model 3, yaitu 11,33 $\mathrm{cm}$ dan yang paling kecil simpangannya adalah pada Model 2, yaitu 10,16 cm. Perbedaan besar simpangan ini terjadi karena berbedanya model penahan gaya lateral pada struktur tersebut. Pada model gedung 1, kekakuan leteral struktur gedung di topang oleh balok dan kolom saja, pada Model gedung 2 dan 3 kekakuan lateral struktur gedung ditopang sebagian besar oleh dinding geser sehingga lebih kaku, tetapi pemodelan dinding geser ini juga menyebabkan berbedanya kekakuan struktur dan besar simpangannya. Dinding geser solid element adalah pemodelan dinding geser dengan menggunakan element shell thin pada SAP2000, sedangkan dinding geser line element adalah pemodelan dinding geser dengan menggunakan element frame/kolom pada SAP2000 yang diperlebar menyerupai dinding.

\section{Simpulan}

Dari hasil analisa yang telah dilakukan pada ketiga model struktur, model struktur tanpa dinding geser (Model 1), model struktur solid element (Model 2) dan model line element (Model 3), maka dapat diambil kesimpulan bahwa akibat perbedaan cara pemodelan elemen struktur maka akan terjadi perbedaan pada perioda getar struktur, gaya geser dasar dan gaya-gaya dalam. Perbedaan juga terjadi pada lamanya waktu run analysis pada program analisa struktur. Perbedaan-perbedaan ini terjadi diakibatkan oleh perbedaan model sistem pengaku.

\section{Daftar Pustaka}

Badan Standarisasi Nasional. 2012. Tata Cara Perencanaan Ketahanan Gempa Untuk Struktur Bangunan Gedung dan Non Gedung SNI 1726:2012, Jakarta, Departemen Pekerjaan Umum.

Budiono, B. dan Supriatna, L. (2011). Studi Komparasi Desain Bangunan Tahan Gempa Dengan Menggunakan SNI 031726-2002 dan SNI 1726:2012. Bandung ITB

Departemen Pekerjaan Umum. 1987, Pedoman Perencanaan Pembebanan Untuk Rumah dan Gedung, Jakarta: Yayasan Badan Penerbit PU.

Direktorat Penyelidikan Masalah Bangunan. 1981, Peraturan Pembebanan Indonesia Untuk Gedung 1983. Bandung: Yayasan Lembaga Penyelidikan Masalah Bangunan.

Frans. Y, (2014), Shearwall. http://id.scribd.com/doc/134521917/589427 78-Shear wall. Diakses 3 Desember 2014

Hasan, A dan Astira, I.F. (2013). Analisis Perbandingan Simpangan Lateral Bangunan Tinggi Dengan Variasi Bentuk dan Posisi Dinding Geser. Studi Kasus: 
Proyek Apartemen The Royale Springhill Residences. Palembang. Program Studi Teknik Sipil, Universitas Sriwijaya.

Imran, I. dan Hendrik, F. (2009), Perencanaan Struktur Beton Bertulang Tahan Gempa Berdasarkan SNI 03-2847-2002. Bandung: ITB.

Imran, I. Yuliari, E. Suhelda dan Kristianto, A. (2008). Aplicability Metoda Desain Kapasitas pada Perancangan Struktur Dinding Geser Beton Bertulang, Seminar dan Pameran HAKI, "Pengaruh Gempa dan Angin terhadap Struktur". Hal. 110.

Indarwanto. M (2009), Shear Wall. http://kk.mercubuana.ac.id/elearning/ filesmodul/12029-6-881560689835.doc. Diakses 3 Desember 2014

Irawan, H.R.N. (2014). Analisa Torsi Pada Lantai Struktur Tidak Regular Horizontal Pada Daerah Rawan Gempa Tinggi Dan Rendah. Laporan Tugas Akhir. Medan. Program Studi Teknik Sipil.UMSU

Ismanto. R (2009). Dasar-Dasar Perancangan Bangunan Tahan Gempa Untuk Arsitek Desainer. Jakarta. FT. UBINUS

Marques. M (2014), Sistem Struktur Bangunan Tinggi. http://www.scribd.com /doc/230053238/r-017456298\#scribd.

Diakses 3 Desember 2014

Pakpahan R.H (2009). Analisis Perencanaan Dinding Geser Dengan Metode Strut And Tie Model. Laporan Tugas Akhir. Program Studi Teknik Sipil. Medan. USU

Pawirodikromo, W. (2012). Seismologi Teknik \& Rekayasa Kegempaan. Yogyakarta .Universitas Islam Indonesia

Standar Nasional Indonesia. 2002. Tata cara perhitungan struktur beton untuk bangunan gedung. Bandung. Departemen Pekerjaan Umum.

Wiryanto (2010), Detailnya Aneh, Betul Nggak Sih Pak? https://wiryanto. wordpress.com/2010/10/23/detailnya-anehbetul-nggak-sih-pak/. Diakses 11 Juni 2015

Yuliari, E. dan Suhelda. (2008). Evaluasi Perbandingan Konsep Desain Dinding Geser Tahan Gempa Berdasarkan SNI Beton. Laporan Tugas Akhir. Bandung: Program Studi Teknik Sipil, ITB 